\author{
М. С. Николова \\ Университет библиотековедения и информационных технологий \\ (Республика Болгария)
}

\title{
БОЛГАРСКИЙ ОПЫТ В СОХРАНЕНИИ ПРАВОСЛАВНЫХ ХРАМОВ
}

\begin{abstract}
В статье изложены и обобщены результаты работы по научному проекту ДН 15/4 «Создание модели для сохранения, социализации и популяризации христианских церквей в Болгарии». Уже третий год группа преподавателей, соискателей и студентов Университета библиотековедения и информационных технологий (г. София, Болгария) разрабатывает данный научный проект. В статье представлены различные действия и местные политики по сохранению христианских храмов, которые являются результатом исследований, проведенных на местах в трех областях Болгарии. Выявлены зависимости действий и местных политик и программ по сохранению храмов от особенностей развития конкретной области. В Варненской области подчеркнута роль храмов в развитии туризма; в Смолянской области было установлено, что жива и поддерживается многолетняя традиция заботы о православных храмах, которые здесь воспринимаются не только как молитвенный дом, но и как средство для сохранения болгарской идентичности. В области Болярово было установлено современное развитие действий местной власти и населения по сохранению храмов, находящихся на границе с Турцией, и тех, что остались на территории Турции.
\end{abstract}

Ключевые слова: проект ДН15/4, православие, храмы, сохранение.

Для цитирования: Николова М. С. Болгарский опыт в сохранении православных храмов // Труды БГТУ. Сер. 6, История, философия. 2021. № 1 (245). С. 102-106.

\section{S. Nikolova \\ University of Library Science and Information Technologies (Republic of Bulgaria) \\ BULGARIAN EXPERIENCE IN THE PRESERVATION OF ORTHODOX CHURCHES}

The article presents and summarizes the results of the work on the research project DN 15/4 "Creating a model for the preservation, socialization and popularization of Christian churches in Bulgaria". For the third year, a group of teachers, applicants and students of the University of Library Science and Information Technology, Sofia, Bulgaria, has been developing this research project. The article presents various actions and local policies and programs for the preservation of Christian churches, which are the result of on-site research conducted in three regions of Bulgaria. The dependence of actions and local policies for the preservation of churches on the peculiarities of the development of a particular area is revealed. In the Varna region, the role of churches in the development of tourism was emphasized; in the Smolyan region, it was found that the long-standing tradition of caring for churches is alive and maintained, which are perceived here not only as a house of worship, but also as a means to preserve the Bulgarian identity. In the Bolyarovo region, the modern development of the actions of the local authorities and the population to preserve the temples located on the border with Turkey and those remaining on the territory of Turkey was established.

Key words: project DN15/4, Orthodoxy, churches, preservation.

For citation: Nikolova M. S. Bulgarian experience in the preservation of orthodox churches. Proceedings of BSTU, issue 6, History, Philisophy, 2021, no. 1 (245), pp. 102-106 (In Russian).

Введение. Изучение культурно-исторического наследия как совокупности религиозных, культурных, художественных, интеллектуальных, материальных и нематериальных артефактов, накопленных в разные исторические периоды и ставших органической частью ценностей региона, нации и страны, является научной проблемой, требующей решения различных исследовательских задач [1].

Группа преподавателей, соискателей и студентов Университета библиотековедения и информационных технологий поставила перед собой задачу в рамках научного проекта ДН 15/4
«Создание модели для сохранения, социализации и популяризации христианских церквей в Болгарии» изучить конкретные проблемы защиты православных церквей в Болгарии.

Вопрос сохранения и популяризации христианских православных памятников в Болгарии актуален по нескольким причинам:

1. Болгария - это страна, в которой на протяжении веков население в некоторых районах было и есть мультирелигиозным.

2. Христианское население Болгарии на протяжении веков и по сей день поддерживает, 
строит и заботится о памятниках православного христианства, что является традиционной формой сохранения своей религиозной принадлежности и национальной самобытности.

3. Наряду со старыми храмами болгарыпатриоты построили новые храмы и часовни, взяв на себя их полное содержание.

4. Во многих населенных пунктах, удаленных от основных дорог, возводятся старые церковные храмы, история, настоящее и будущее которых заслуживают подробного изучения, документирования и сохранения.

Основная часть. Современное отношение болгарского населения к памятникам православного христианства выражается как в хорошем знании и продолжении традиций, так и в порождении множества идей и мероприятий по их сохранению. В связи с этим на местном уровне реализуются различные инициативы, имеющие общую цель - сохранение, приумножение и популяризацию православных памятников христианской культуры, значимых для самоидентификации жителей разных регионов страны. В этих инициативах принимают участие представители государственных и местных властей, представители культурных учреждений, общественных организаций, а также люди, желающие и имеющие финансовые возможности для строительства и обслуживания христианских памятников.

Работа по проекту была проведена исключительно на месте, а данные о изучаемой проблеме были собраны разными методами. Сначала была проведена базовая анкета среди представителей местной власти и культурных учреждений и в результате были определены параметры исследований. На месте были проведены встречи и беседы с представителями мэрии, представителями региональных музеев, с представителями Болгарской православной церкви (БПЦ) и с обыкновенными жителями. Беседы велись по следующим вопросам:

- Каково состояние храмов на территории их области?

- Какие действия совершаются по их сохранению и реставрации?

- Как местная власть и Болгарская православная церковь решают проблемы, есть ли между ними согласие и единодействие?

- Кто является основным спонсором для строительства новых храмов?

- Как местное население и власть популяризируют свой храмы?

Это были основные вопросы, вокруг которых велись разговоры в трех исследованных областях, но по ходу бесед возникали и новые, тоже существенные проблемы, которые получали свои решения в зависимости от местной политики.
По проекту проведены исследования в трех областях Болгарии: Варненская, Смолянская и Болярово. Каждая из выбранных областей раскрывает отдельные стороны и специфики заботы населения, местной власти и Болгарской православной церкви (БПЦ) о храмах на конкретной территории, но, одновременно с этим, определяет общие действия и инициативы, которые характерны для всего болгарского населения и его отношения к религиозному наследию.

Область Варна характерна тем, что там расположено множество православных церквей, которые являются объектом не только поклонения, но и туристического времяпрепровождения. Туристический интерес к региону понятен - область Варна давно зарекомендовала себя как современный и востребованный морской курорт. Нужно отметить особенный интерес туристов не только к природным богатствам, но и к разнообразному культурному наследию региона: Римские бани, Региональный исторический музей г. Варна, природный заповедник «Побитые камни», кафедральный Собор Успения Пресвятой Богородицы (рис. 1), музейный комплекс «Монастырь Аладжа», монастырь Святых Константина и Елены на курорте Святых Константина и Елены, а также множество церквей в небольших поселениях.

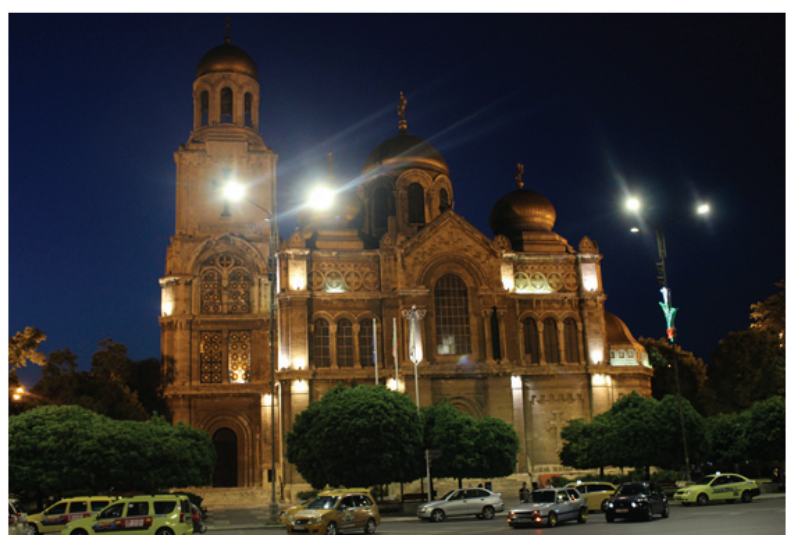

Рис. 1. Кафедральный собор Успения Пресвятой Богородицы г. Варна

Наш исследовательский интерес к Варненскому району вызван активными действиями местных властей по защите, развитию и популяризации культурного наследия на его территории. Муниципалитет активно сотрудничает с Варненским митрополитом, совместными усилиями и средствами строятся новые храмы, а старые поддерживаются и реставрируются.

В области Варна множество объектов культурного наследия, в т. ч. религиозного, включены в туристические маршруты. Наиболее важным из них является музейный комплекс «Монастырь Аладжа», который решением 
Совета Министров от 2015 г. находится под управлением муниципалитета Варны вместе с другими объектами, имеющими статус археологических недвижимых культурных ценностей. Речь идет о Римских банях Одессоса, епископальной базилике Одессоса, Варненском энеолитическом некрополе и княжеском монастыре. Срок управления - 10 лет. Таким образом, можно сохранить обнаруженные археологические ценности, ускорить реализацию проектов по их демонстрации и социализации, а также организовать культурные мероприятия на открытом воздухе местными властями при активном участии других учреждений, отдельных граждан и представителей бизнеса. Местная политика защиты православных церквей создает модель управления и их социализации, включая их в туристические маршруты.

В Варненской области храмы, старые и более новые, являются существенным элементом услуг, предоставляемых многочисленным туристам. Мы установили, что самое существенное в этой области - это великолепный пример популяризации и социалидации православных храмов. Гордость города - это великолепный кафедральный собор Успения Пресвятой Богородицы, который находится в самом центре и является главным туристическим объектом. Болгарская православная церковь, мэрия и государство выделили более полумиллиона левов на ремонт храма, на консервацию его икон и стенописей. Кроме того, гражданами, юридическими лицами, Болгарской православной церковью, мэрией и государством были выделены немалые средства на строительство нового собора в честь покровителя города - Святого Прокопия Варненского.

В Болярово, второй из выбранных областей, вся политика и действия местного населения, бизнеса и власти по отношению к сохранению старых и строительства новых храмов развиваются по подобию действий во всей стране. Специфика здесь в том, что эта область граничит с Турцией и множество действий и политик по отношению православных храмов проводятся по программе трансграничного сотрудничества. В результате на территории района Болярово восстановлено множество храмов в маленьких селах, а также отдельные храмы в деревнях на территории Турции. Особенно важны два больших православных храма в г. Эдирне: храм Святого Георгия и Храм Святых Константина и Елены (рис. 2). Деньги на это получены от жителей, юридических лиц и местной власти, а также по различным европейским программам. Таким образом восстановлены храмы в г. Болярово, и г. Елхово, и селе Стефан Караджа и пр.
Смолянская область предоставила нам самый интересный материал для исследования, потому что в этом районе отношение населения к храмам более сложное. В нем часть жителей много десятилетий исповедуют ислам, и в историческом плане для православных забота о храме выражается и в заботе о сохранении национальной идентичности.

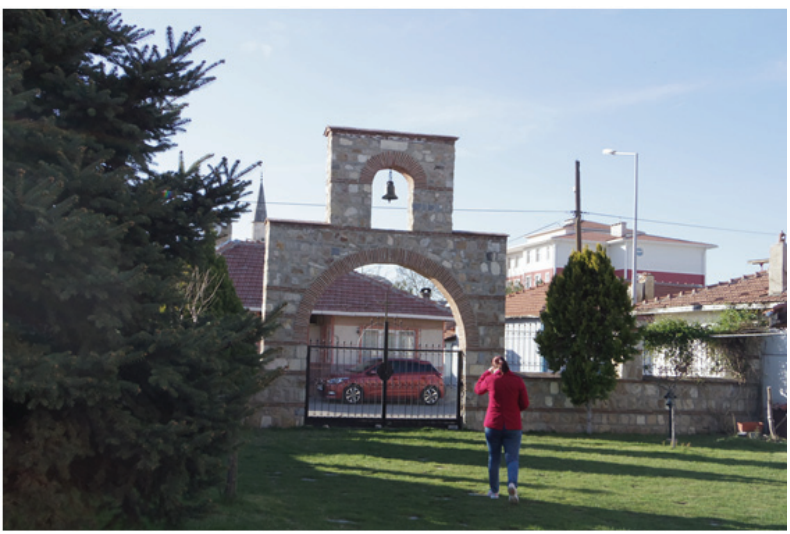

Рис. 2. Восстановленная православная церковь Святых Константина и Елены в г. Эдирне, Турция

В этом горном и труднодоступном регионе построено много церквей - маленьких, вкопанных в землю, скромных снаружи и богато украшенных изнутри. Местное население, несмотря на то, какую религию исповедует, заботится о своем православном наследии. Например, как относится к своим храмам население самого южного болгарского города Златоград, в котором веками дружески живут православные и мусульмане.

Недалеко от города, на холме Святой Недели (Света Неделя), по предложению рода Молевых и других жителей, вместе с тогдашним священником Отцом Атанасом Аролски (1919-2015) была восстановлена большая часовня Святой Недели. Сам отец Аролски рассказывал, как он вместе с магометанами на руках поднимали на вершину огромные деревья, чтобы восстановить старый, разрушенный когда-то турками храм. Это над городом, глубоко в лесу, и когда храм был готов, горожане сами проложили туда дорогу. С разрешения местных властей каждая семья получила возможность построить «хижину» (как их называют жители) вокруг часовни и проводить там свободное время. Многие воспользовались возможностью, и теперь вокруг часовни возводятся небольшие «хижины». Сама часовня в очень хорошем состоянии, дорога к ней хоть и крутая, но отличная. На праздник храма собирается практически весь город, независимо от того, кто какую религию исповедует, и все вместе празднуют.

Отец Аролски, который 52 года служил в городе, рассказывал, что в годы, когда верующим было запрещено ходить в церковь, жители, 
исповедующие ислам, привезли дрова, чтобы в храме было тепло. Они же отремонтировали крышу церкви. Отец рассказывал, что в городе никто не делает разницу, кто какому Богу молится. Златоград известен и тем, что в городе кладбище общее, и он и сегодня является примером верской терпимости.

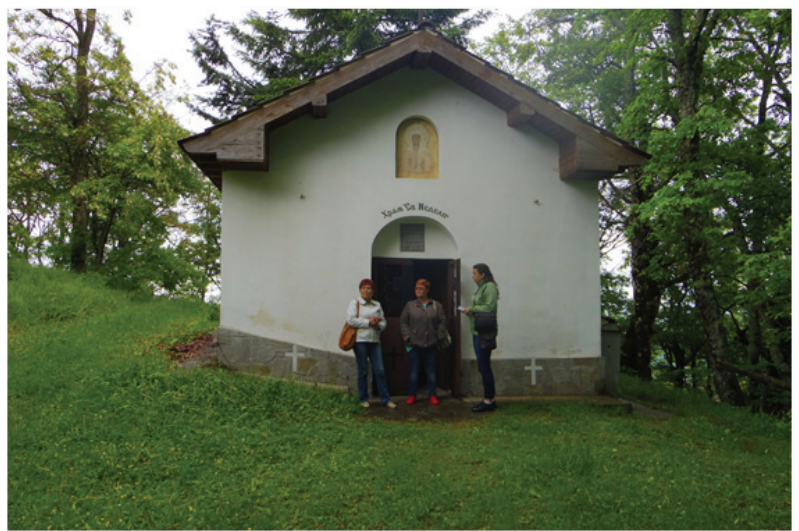

Рис. 3. Восстановленная большая часовня Святой Недели в горах над г. Златоград

Различные инициативы по реставрации старых храмов мы нашли во многих местах Смолянского района: в городе Чепеларе, в селах Чокманово, Павелско, Широка Лыка. Особо отметим, что происходит по отношению восстановления и сохранения храмов в селе Чокманово: знаменательное по отношению к православным церквям не только в районе, но и по всей стране. В этой деревне старые храмы своими руками и на свои средства восстанавливает местный житель Атанас Иванов.

С ним мы встретились в Чокманово и он сразу на своей старой машине повез нас глубоко в горы и по дороге рассказывал, почему и как восстанавливает разрушенные часовни. Он начал реставрацию часовен пятнадцать лет назад, после смерти своего отца. Сам родился в Смоляне, но его бабушка из Чокманово. На наш вопрос, зачем он это делает, Атанас Иванов ответил: «Факторов много. Много лет назад, когда я вернулся сюда, мой отец умер. Тогда я жил в Варне, у меня был свой маленький бизнес. Когда отец заболел, он начал восстанавливать одну из старейших часовен храм Святых Косьмы и Дамиана - святых целителей (рис. 4). Отец знал о своей неизлечимой болезни и втайне надеялся на исцеление. Но не успел довести свое дело до конца. Я вернулся сюда, закончил часовню, а потом продолжил сам».

Теперь ему почти шестьдесят, живет один, продал бизнес, свой дом и на деньги строит храмы. До прошлого года он построил пятнадцать. Они расположены в горах, высоко и далеко, но на местах, где в древности были хра- мы. Смысл всего, что он делает, он видит в следующем: «Не дай Бог, чтобы деревня не исчезла с карты Болгарии, потому что там осталось двадцать человек. Эта вера в людей какимто образом зажигает их сердца, чтобы они не забывали, кто мы есть. Потому что учебники и тому подобное уже меняются. Патриотизм это не просто похлопывание по груди и не слова, что вы большой патриот, или зажигание свечей. Я очень редко хожу в церковь. В году на Пасху и Рождество, потому что в остальное время я постоянно в храмах, и для всего нужно время. Это моя дорога, это мой дом здесь».

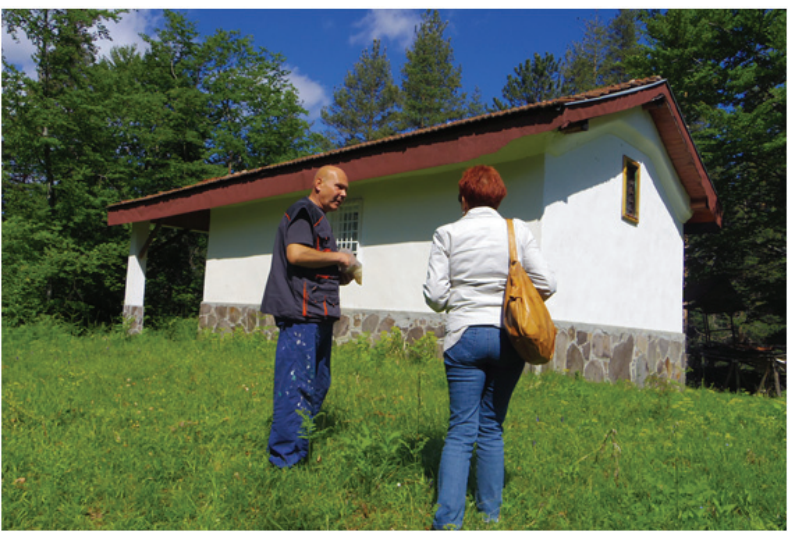

Рис. 4. Атанас Иванов у восстановленной часовни Святых Косьмы и Дамиана в селе Чокманово

В городе Смолян, в самом центре города, появилась новая церковь Святого Виссариона Смоленского (рис. 5).

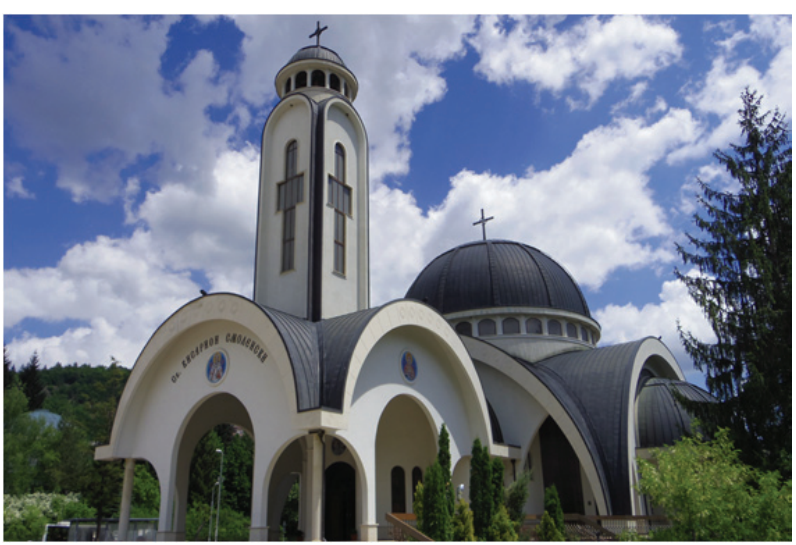

Рис. 5. Храм Святого Виссариона Смоленского в центре г. Смолян

Масштаб проекта впечатляет - это один из самых больших соборов не только района, но и Болгарии. Он был построен по инициативе самого крупного бизнеса страны, а также жителей города и области. Государство, муниципалитет и Болгарская православная церковь также участвуют в строительстве церкви. Храм был освящен 2 июля 2006 г. Пловдивским митрополитом 
Арсением. Построен на месте старой церкви кладбищенской часовне XIX в., посвященной святому Тодору.

Храм имеет уникальные колокола, заказанные спонсорами в России. Церковь действующая и, помимо прихожан, своей необычной архитектурой и монументальностью привлекает множество туристов.

Заключение. Во всех исследуемых областях мы встретили много разных людей: представителей власти, Болгарской православной церкви, культурных учреждений, простых граждан. Все они были разные, но объединяло их одно - их невероятная любовь и привязанность к своей родине, своему культурному наследию, своей религии и своим храмам. Они не просто проявили привязанность, они сделали все, чтобы сохранить для поколений религиозную память, которая отмечает национальную идентичность.
Бережное отношение и хорошие практики для сохранения религиозного культурного наследия характерны для каждого региона страны. Во всех областях, которые мы изучали, мы обнаружили заботливое отношение властей, учреждений культуры и населения к православным церквям.

В заключение можно сказать, что на территории Болгарии существует хорошо функционирующая модель защиты, социализации и популяризации православных христианских церквей. Чрезвычайно бережно относятся к молитвенным домам представители Болгарской православной церкви, местные власти, бизнес и, прежде всего, местное население. Наши наблюдения показали, что болгарин, независимо от места проживания, профессии, финансового состояния готов сделать и много делает для сохранения своих храмов.

\section{Список литературы}

1. Закон за културното наследство: Закон Респ. Болгарии от 10.04.2009: с изм. и доп. от 13.05.2020 // Дьржавен вестник / Министерство на регионалното развитие и благоустройството. София, 2021. URL: https://www.mrrb.bg/bg/zakon-za-kulturnoto-nasledstvo (дата обращения: 31.01.2021).

2. Богова Х., Мюмюн Т. Критична теория на културата или културата като процес на хуманизация // Съвременни измерения на европейското образователно и научно пространство. Т. 8. София: За буквите - О писменехь, 2020.

\section{References}

1. Zakon za kul'turnoto nasledstvo [Cultural Heritage Act]: Law of the Republic of Bulgaria dated 10.04.2009. Available at: https://www.mrrb.bg/bg/zakon-za-kulturnoto-nasledstvo (accessed 31.01.2021).

2. Bogova Kh., Myumyun T. Critical theory of culture or culture as a process of humanization. $S^{\prime \prime}$ vremenni izmereniya na evropeyskoto obrazovatelno i nauchno prostranstvo [Contemporary dimensions of the European educational and scientific space], 2020, vol. 8 (In Bulgarian).

\section{Информация об авторе}

Николова Мария Стефанова - кандидат филологических наук, профессор. Университет библиотековедения и информационных технологий (1784, г. София, бул. Цариградско шосе, 119 , Республика Болгария). E-mail: m.nikolova@unibit.bg

\section{Information about the author}

Nikolova Maria Stefanova - PhD (Philology), Professor. University of Library Science and Information Technologies (119, Tsarigradsko Shosse Blvd, 1784, Sofia, Republic of Bulgaria). E-mail: m.nikolova@unibit.bg 